\title{
Vulnerability of island countries in the South Pacific to sea level rise and climate change
}

\author{
Nobuo Mimura* \\ Center for Water Environment Studies, I baraki University, Hitachi, Ibaraki 316-8511, J apan
}

\begin{abstract}
An assessment of the vulnerability to sea level rise and climate change was performed for island countries in the South Pacific (Tonga, Fiji, Samoa, and Tuvalu) under the collaboration of J apanese experts and the South Pacific Regional Environment Programme. A combination of experiencebased and scientific methods were developed to reveal the overall vulnerability of and possible impacts on the coastal zone sectors. The studies identified the common impacts on and vulnerability of these countries. Inundation and flooding are the common threats to these islands because of their low-lying setting; the problem is exacerbated by the social trends of population growth and migration to main islands, in particular to the capital cities. Other threats include beach erosion, saltwater intrusion, and impacts on the infrastructure and coastal society. For the island countries, the response to sea level rise and climate change focuses on adaptation rather than on reduction of greenhouse gas emissions (that is, mitigation). Based on the results of the vulnerability assessment, the concept of and options for adaptation are also discussed.
\end{abstract}

KEY WORDS: Sea level rise · Vulnerability · Adaptation · Island countries · South Pacific

\section{INTRODUCTION}

Small island countries are among the most vulnerable to future sea level rise and climate change (for example, see IPCC 1996). To respond to the urgent need to assess the vulnerability and establish response strategies for the island countries in the South Pacific, a series of studies have been carried out since 1992 under the collaboration of J apanese experts and the South Pacific Regional Environmental Programme (SPREP). The study countries were Tonga (Fifita et al. 1992, M imura \& Plesikoti 1997), Fiji (Nunn et al. 1993, 1994a, 1996), Samoa (Kay et al. 1993, Nunn et al. 1994b), and Tuvalu (Sem et al. 1996). The aim of these studies was to identify the vulnerability and resilience of the coastal natural and socio-economic systems of each country using a variety of approaches. The studies included (1) vulnerability assessment ranging from overall assessment and classification of coastal zones with vulnerability indices to evaluation of impacts on

*E-mail: mimura@hcs.ibaraki.ac.jp infrastructure, (2) analysis of coastal erosion and shoreline protection, (3) economic evaluation of response options, and (4) examination of adaptive options. The present study aims to show the characteristics and degree of the threats to these island countries induced by sea level rise and climate change, and to identify conceptual options for adapting to such threats through a synthesis of the studies.

\section{APPLIED METHODS}

The Intergovernmental Panel on Climate Change (IPCC) Common M ethodology (IPCC CZM S 1991) was developed as a framework for the vulnerability assessment of individual countries, in which a set of specific data for natural and socio-economic conditions is required and the impacts are often evaluated on an economic basis using gross domestic product (GDP) as a typical index. However, we were hampered by the lack of data, such as topographic maps with precise contours, historical records of climate and mean sea level, land use pattern, and so forth - a constraint that 
is common in developing countries. In addition, the monetary economy is only a part of a country's economic system, and a subsistence economy still prevails in the South Pacific. These factors restricted the direct application of the IPCC Common M ethodology. Therefore, various approaches needed to be developed using available data and methods.

An important aspect is to use the traditional knowledge and memories of the local people to overcome the shortage of data. Indigenous people have been living in the same villages and have observed environmental changes for generations. The memories and experiences of people living in long-established local settlements are an effective source of information. Based on such recognition, a semi-empirical method has been developed to enable systematic analysis of coastal vulnerability by expert judgment. This method classifies the coastal system into 6 subsystems-natural, human, infrastructural, economic, institutional, and cultural-as shown in Fig. 1, and evaluates their resilience and vulnerability to changes in external forces, such as sea level rise (Kay \& Hay 1993). A set of criteria for expert judgment was established to evaluate the degree of vulnerability and resilience of the subsystems on a common basis (Yamada et al. 1995). This method allowed us to draw an overall picture of the vulnerability of the entire country or island.

A similar approach was applied to the analysis of beach erosion. Interviews regarding beach erosion and coastal protection practices were carried out with elderly people in local villages. On the basis of the

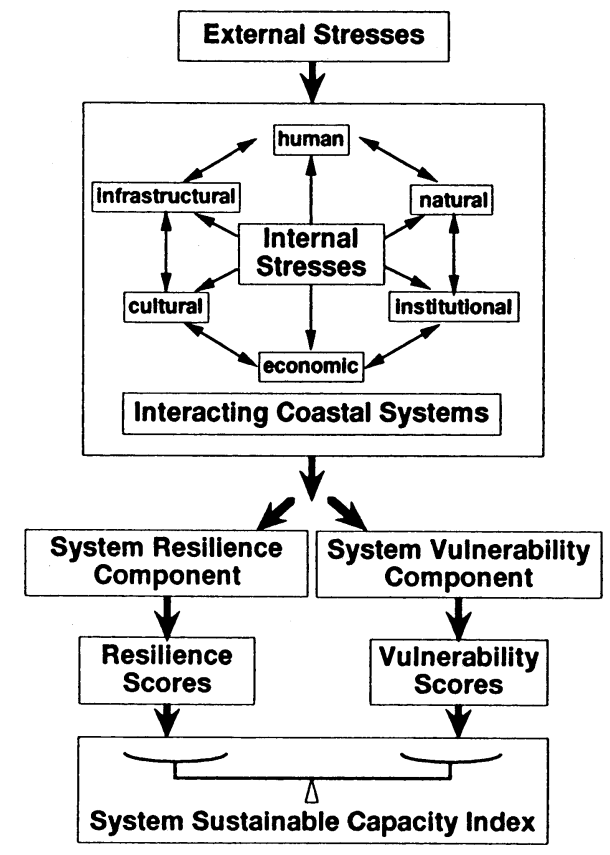

Fig. 1. Framework of the semi-empirical assessment method information collected in these interviews, a long-term trend in beach erosion was analyzed from the viewpoint of the future sea level rise and climate change.

In addition to assessing impacts qualitatively, analytical science and engineering tools were also applied. Storm surge, wave height and run-up, and wave forces on wharfs, seawalls, and concrete blocks were estimated using coastal engineering to evaluate the changes in external forces and their consequences. A Geographic Information System (GIS) was applied for the Fiji study to classify the coastal zones in terms of vulnerability indexes, and economic evaluation was done in the Tuvalu study to analyze the costs of countermeasures to sea level rise (Ohno et al. 1996).

The methods developed during the studies combined experience-based and scientific ones. Using such a combination, we could reveal the overall vulnerability qualitatively, while evaluating the impacts on some coastal systems quantitatively. This approach was helpful to compensate for the lack of data. However, the present methods do not cover all the related sectors in the coastal zone. To develop a response strategy based on the estimate of all the possible threats, we would need a set of quantitative methods and the relevant data.

\section{VULNERABILITY OF THE SOUTH PACIFIC ISLAND COUNTRIES}

The primary impacts of sea level rise are increased risk of inundation and coastal flooding, exacerbation of erosion, saltwater intrusion into rivers and underground aquifers, and changes in sediment deposition patterns (IPCC WGIII 1990). These are all changes in the physical environment in the coastal zone, and their implications and severity for ecosystems and human society differ with the geographic and social conditions. However, there is some commonality in the vulnerability of the studied countries, which characterizes the island countries in the South Pacific (Nunn \& Mimura 1997).

\subsection{Inundation and flooding}

Among the studied countries, the main islands of Fiji, Tonga, and Western Samoa are all comparatively large and high islands. Large portions of their coastlines consist of coral limestone and/or hard lava, which resist wave action. On these islands, however, the population is concentrated on narrow, low-lying areas fringing the mountains along the coast. Even though the area of the whole island is large and the average elevation is high enough, the economic activities are 
mostly concentrated on the coast. The capital of each of these 3 countries is situated on a large coastal area. Therefore, the effects of inundation and flooding are not small for them.

Fig. 2 shows the areas below the elevation of 1 to $4 \mathrm{~m}$ above the present coastline (high-water level) in Togatapu Island, Tonga. Lowlands extend along the north shore, and the land is particularly low at Nuku'alofa, the capital. Increases of 0.3 and $1 \mathrm{~m}$ in mean sea level (MSL) would cause land loses of 3.1 and $10.3 \mathrm{~km}^{2}$, respectively, or 1.1 and $3.9 \%$ of the total area of Tongatapu Island. A bout 2700 and 9000 people would be affected under the 2 scenarios, corresponding to 4.3 and $14.2 \%$ of the total population of Tongatapu, respectively. In the case of an extreme event, about 20000 people currently live in the low-lying areas that can be flooded by a storm surge of $2.8 \mathrm{~m}$, which was recorded during cyclone Isaac in 1982. If

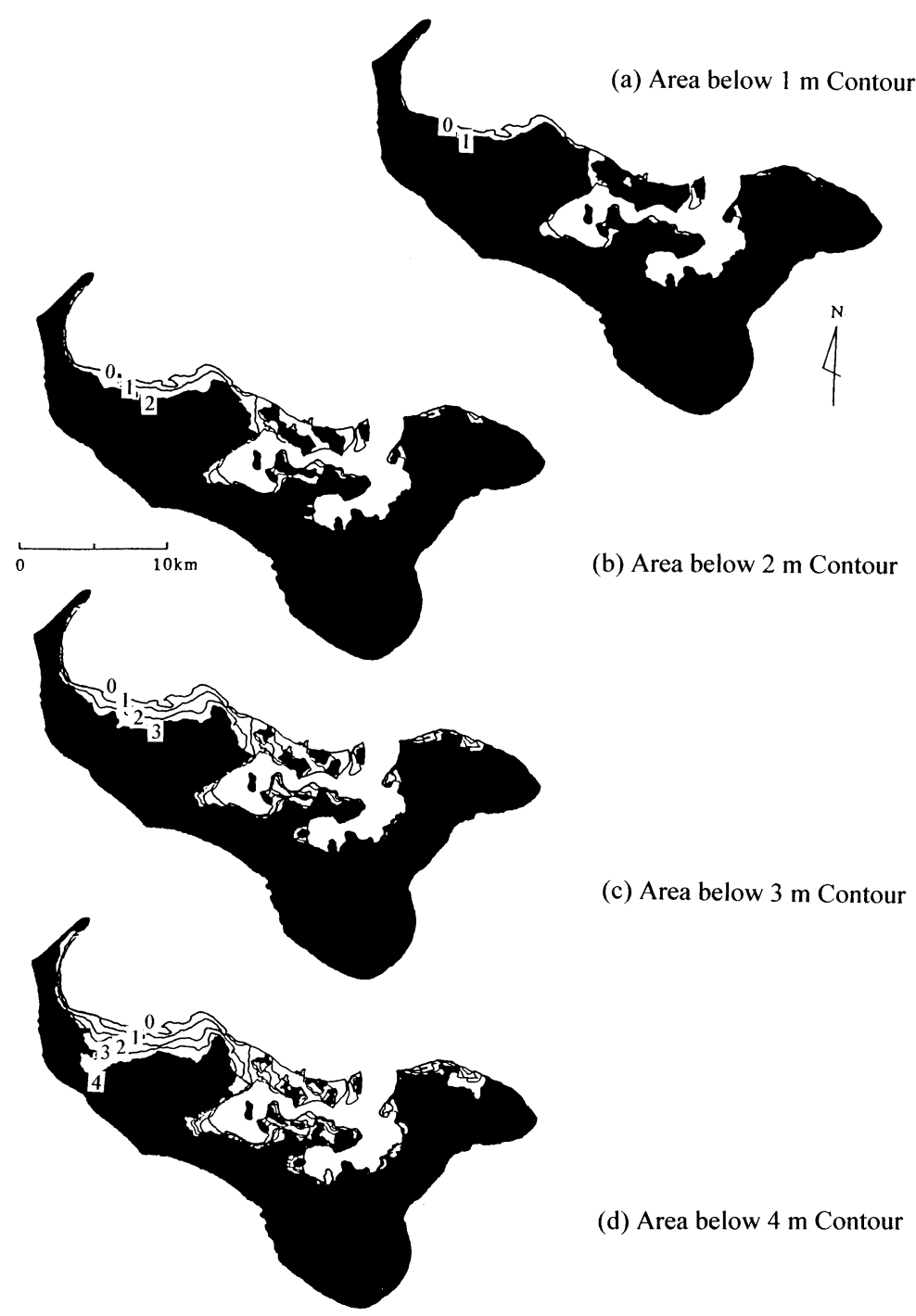

Fig. 2. Areas at risk in Tongatapu Island, Tonga a storm surge of the same degree occurs in conjunction with a $0.3 \mathrm{~m}$ sea level rise, $27.9 \mathrm{~km}^{2}$ (11\% of the Tongatapu Island) and 23470 people (37\% of the Tongatapu population) would be at risk. These increase to $37.3 \mathrm{~km}^{2}(14 \%)$ and 29560 people (46\%) for a $1 \mathrm{~m}$ sea level rise. It should be noted that the impacts of sea level rise are not limited to simple inundation and that the danger of cyclone-induced storm surge increases significantly (Fifita et al. 1992, M imura \& Plesikoti 1997).

The risk of inundation and flooding is further intensified by social factors. In recent years, many countries in the South Pacific have experienced the migration of people from outer islands to the capitals, and a sharp increase in the population of the low-lying coastal areas. Such migration is often associated with economic difficulties, and the land-ownership system does not allow the migrants to buy new land in some countries. Therefore, people tend to live in very low and unsafe areas, such as a lagoon coast in Nuku'alofa, Tonga. Such population pressure also drives intensive landfills along the coasts. All of these social tendencies make the areas surrounding and including these islands' capitals very vulnerable to sea level rise and climate change.

The extreme impact of inundation and flooding is to make the very low-lying islands uninhabitable. Owing to sea level rise and flooding induced by a higher water table, it is anticipated that people currently living on very low islands would have to move to other islands and areas. Funafuti, Tuvalu, is an example of such an island among the ones that were studied; the elevation is extremely low, with a mean elevation of about $1.5 \mathrm{~m}$ above MSL, and sealevel rise would shorten the return period of storm surges and exacerbate the damage caused by wave overwash (Sem et al. 1996). Even if small islands are not currently inhabited, inundation of such islands means a loss of territorial seas and a reduction in the extent of their exclusive economic zones.

\subsection{Beach erosion}

Another common concern in the South Pacific is the exacerbation of beach erosion. The countries have all experienced an increased rate of shoreline retreat over the past several decades. Typical examples can be seen in Viti Levu, Fiji (Mimura \& Nunn 
1997). Table 1 shows the distribution of the decades when the coastal villages first constructed seawalls, which was summarized from the interviews with elderly people of 29 coastal villages. It is apparent that most villages did not try to build seawalls before 1960, and that the number of seawalls increased after the 1960s. This means that, in all but a few cases, the coastal villages did not need to protect their shorelines from erosion or inundation before 30 to $40 \mathrm{yr}$ ago.

Human activities are considerably responsible for the beach erosion in this region. In many places, mangroves were cleared for fuel wood and land reclamation. Beach sands are intensively used as construction material and for decoration of tombs as a social tradition. The supply of sand is very much limited, since the main sources of the sand are the biological activities of the coral reefs. Therefore, the recent retreat of shoreline is partly attributed to such human pressure.

Another possible reason is acceleration of sea level rise. Temperatures in the Pacific have increased at a faster rate than before, at least since 1970, and this may have produced a concurrent rapid sea level rise during this period, although there are no observed sea level data to confirm this. It is anticipated that sea level will rise 2 to 4 times faster than in the past on a global scale. Future sea level rise in conjunction with human pressure will exacerbate beach erosion significantly.

\subsection{Saltwater intrusion}

The most significant effect of saltwater intrusion is on agriculture. A subsistence economy still dominates in the South Pacific, and people grow root crops, bananas, coconuts, and so forth around their villages. Since they are mostly situated on the coast, if saltwater intrudes into aquifers, there will be significant damage to agriculture. This will be most severe for small, low islands. However, precipitation is plentiful in this region, resulting in an abundance of groundwater, so the effects of saltwater intrusion may remain minor for large and high islands, like Viti Levu, Fiji, and Upolu, Samoa. Since there are no systematic studies, quantitative discussions on the effects of saltwater intrusion are not yet possible.

\subsection{Impacts on infrastructure and society}

Another concern associated with sea level rise is the impact on infrastructure. Roads often run along the coast, so they may incur severe damage. Seaports and airports are important facilities that link the island nations with distant countries as well as with other islands. Usually, main seaports and airports are the most modernized facilities in these countries, and they have enough resistance against the existing forces from the sea. In face of future sea level rise, however, their safety and stability need to be examined again. Some of them will have to be raised, reinforced, or both.

All of the problems mentioned above have to do with impacts on the physical components of the coastal systems. These physical changes may lead to changes in social activities and social stability. Generally, the coastal systems in the South Pacific, both natural and social ones, have long adjusted to the indigenous conditions of the region. Recently, the traditional lifestyle started to change. The effects of future climate change and sea level rise may accelerate this trend. If the speed of change is too fast, such social change may produce unstable conditions in these island nations.

\section{CONCEPT OF ADAPTATION}

We have observed the common threats to the South Pacific. For these island countries, the response strategy to sea level rise and climate change has to focus on adaptation, for the projected impacts are so significant and the greenhouse gas emissions from the islands are

Table 1. Distribution of villages in Fiji with seawalls and the periods in which these seawalls were constructed. Villages for which the period of seawall construction was unclear are not included

\begin{tabular}{|c|c|c|c|c|c|c|c|}
\hline \multirow[t]{2}{*}{ Study area } & \multirow{2}{*}{$\begin{array}{c}\text { No. of } \\
\text { villages surveyed }\end{array}$} & \multicolumn{2}{|c|}{ Existence of seawalls } & \multicolumn{4}{|c|}{ Period of seawall construction } \\
\hline & & Seawalls & No seawalls & Before 1960 & $1960 \mathrm{~s}$ & 1970 s & $1980 \mathrm{~s}$ \\
\hline \multicolumn{8}{|l|}{ Viti Levu } \\
\hline Subsiding area & 2 & 2 & 0 & & 2 & & \\
\hline South coast & 9 & 7 & 2 & 1 & 1 & 2 & 3 \\
\hline West coast & 3 & 3 & 0 & & & & 1 \\
\hline North coast & 1 & 1 & 0 & & & & \\
\hline East coast & 10 & 8 & 2 & & 1 & 4 & 2 \\
\hline Subtotal & 25 & 21 & 4 & 1 & 4 & 6 & 6 \\
\hline Taveuni & 4 & 4 & 0 & & 3 & & 1 \\
\hline Total & 29 & 25 & 4 & 1 & 7 & 6 & 7 \\
\hline
\end{tabular}


very low. To find the way to adapt to such impacts, it is important to recognize that natural systems and human society have the ability to respond to the environmental changes. Real impacts appear when such changes overwhelm the ability to respond. It has been recognized that vulnerability has 2 factors: one is the susceptibility of natural and human systems to environmental changes, and the other is their resilience. Vulnerability is determined by the balance of these 2 factors. Therefore, successful adaptation will take place by enhancing the resilience of the systems, and reducing their susceptibility. Important for the resilience of the South Pacific islands to the hazardous forces of the sea are the natural barriers - that is, coral reefs, mangroves, and sandy beaches. They effectively protect and support the safety of lands, coastal ecosystems, and society by reducing the energy of incident forces. Therefore, it is important to preserve them from the viewpoint of adaptation to future climate change and sea level rise.

A nother form of resilience is found in the social system. The rural villages consist of large families forming a mutually supporting system. Their settlement and culture are also strongly tied to the land. In the face of the loss of land by inundation and erosion, the supporting system may be activated to respond to the crisis. However, since these countries are experiencing a transition away from the traditional system to a new one, it is unclear if a new flexible social community will form (Nunn \& M imura 1997).

\section{ADAPTATION OPTIONS}

It is widely recognized that the adaptation strategy consists of various options that fall under 3 basic categories: planned retreat, accommodation, and protection (for example, IPCC WGIII 1990). However, the adaptation strategy involves more than just the technical options. Technical options can only be implemented effectively in an appropriate economic, legal, institutional, and social context. Any plan to construct engineering structures or to change land use requires people's understanding and support, which in turn will be formed through increased awareness of the potential impacts and the need to take action. M oreover, the adaptation strategy will be successful when it is integrated with other policies. Therefore, we can classify the adaptation options in a broad context as shown below.

\subsection{Information options}

Knowledge of the amount and speed of sea level rise and of climate change and their effects is an important basis for establishing adaptation strategies. In addition, people's proper understanding of future threats and planned countermeasures is needed to implement adaptive options. These are necessary precursors to the planning and implementation stages of adaptation. Such measures include monitoring and research to reduce uncertainty in the estimate, and enhancement of people's awareness. Vulnerability assessment itself is also a measure of this kind.

\subsection{Technical options}

This category includes a range of specific measures of planning and engineering for adaptation. Through the studies, suggestions relevant to the islands in the South Pacific were formed focusing on the protection of land and prevention of coastal erosion.

There are many cases where coastal settlements need to construct seawalls for protection or landfill to meet the requirement for land due to population growth, as mentioned above. So far, people have constructed line structures along the coastlines by putting stones or vertical walls as shown in Figs. $3 \& 4$. The largest problem associated with seawalls is inappropriate design. It is necessary to change the concept of the design from the line to 2-dimensional protection utilizing natural protection. If there are coral reefs, mangroves, and sandy beaches from offshore to the shoreline, it is easy to protect against the waves by constructing a simple structure in front of the village, because the waves will have already lost a large portion of their energy. Such 2-dimensional arrangements consisting of natural systems and artificial structures are much more efficient in protecting the land. It was already mentioned that coastal erosion is exacerbated when mangroves and other coastal vegetation have been cleared. Therefore, preservation of natural barriers, such as mangroves, coral reefs and sandy beaches, is important from many viewpoints.

To prepare for future sea level rise and climate change, it is important to increase the height of the ground where people live, or to move to higher land in advance. This is also an effective way to ensure people's safety during storm surges and tsunamis, for seawalls alone cannot sufficiently protect against these events with their extraordinary high water levels.

\subsection{Policy options}

Adaptation policies include disaster prevention, changes in land use planning, improvement and reinforcement of infrastructure, and so forth. It is important to integrate adaptation policies for climate change with 
other policies, such as environmental conservation, coastal management, and national plans for sustainable development. The adaptation strategy is most effective when it is incorporated in and coordinated with the other existing sectoral policies. However, the discussion of adaptation is still in its initial stages; we need more studies to start actual adaptation processes (for example, M aclver 1998).

\section{CONCLUSIONS}

The studies for assessing vulnerability provided a basis for understanding the potential impacts of cli- mate change and sea level rise. Through them, we could also understand the vulnerability characteristics of the island countries in the South Pacific. Lack of data is still one of the largest impediments for the complete assessment of vulnerability in this region. Various methods were developed in the present studies to obtain a comprehensive and quantitative assessment. In spite of the limitations, the studies revealed in a concrete form that the island countries are very vulnerable to future sea level rise and climate change. The next step is to formulate the adaptation strategies in a more specific form, so that they fit the particular situation of each country and the region as a whole.

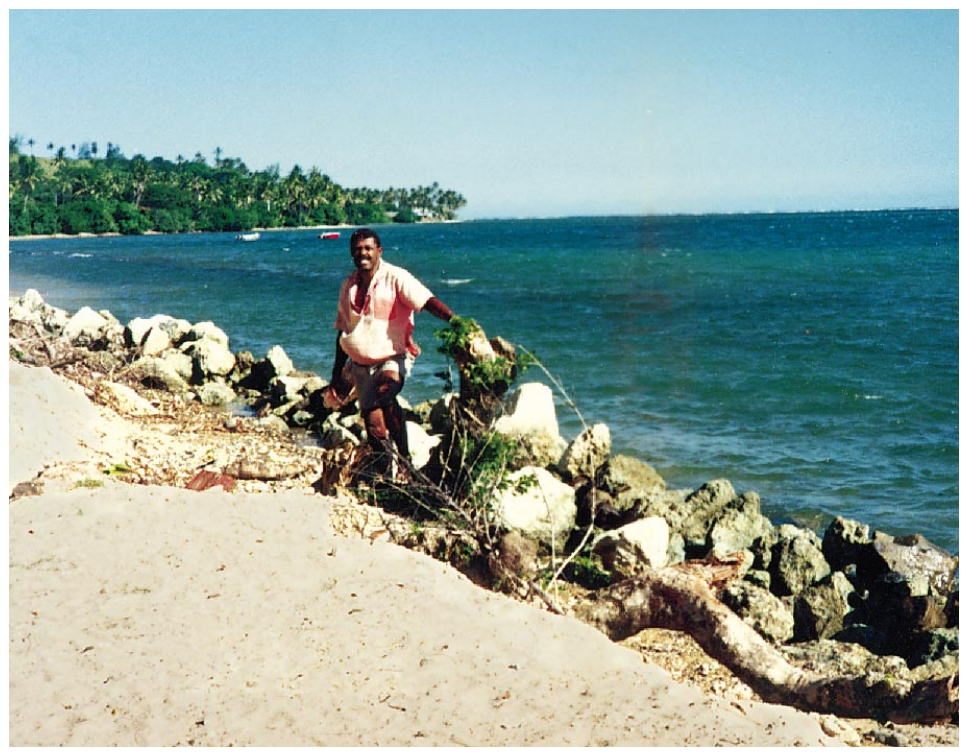

Fig. 3. Coastal protection provided by stones (Viti Levu, Fiji)

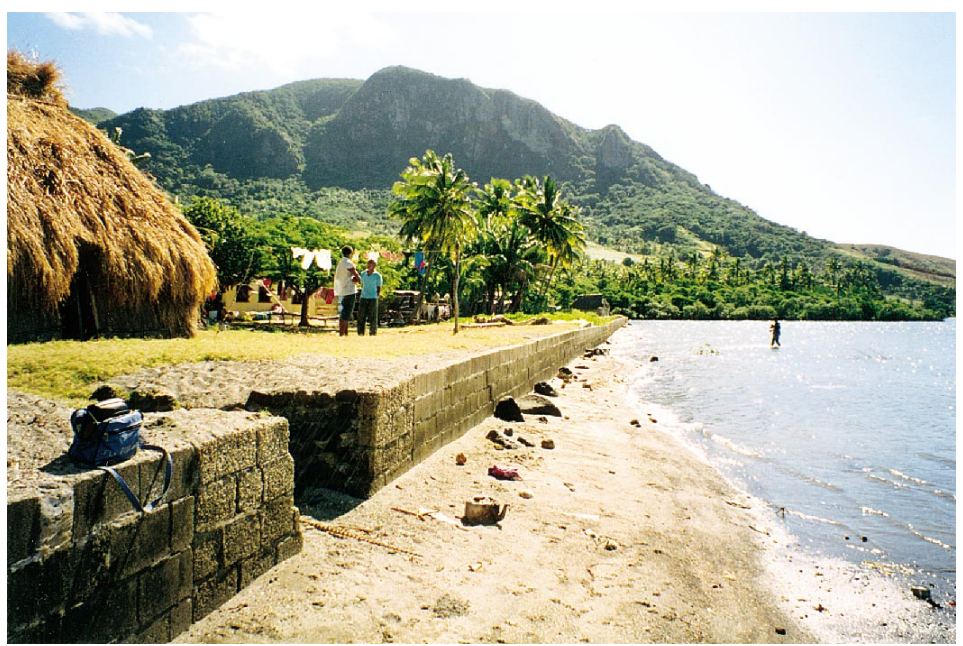

Fig. 4. Vertical seawall (Viti Levu, Fiji)
Acknowledgements. The joint studies were financially supported by the Environment Agency of J apan and the Overseas Environmental Cooperation Center, Japan, and the coordination of the studies was provided by the South Pacific Regional Environment Programme. The author appreciates their strong support. Thanks also go to the members of the international study teams consisting of experts from Japan, Tonga, Fiji, Samoa, Tuvalu, Papua New Guinea, Australia, and New Zealand.

\section{LITERATURE CITED}

Fifita P, Mimura N, Hori N (1992) Assessment of the vulnerability to sea level rise for the Kingdom of Tonga. In: Proceedings of the IPCC/CZMS Workshop. The rising challenge of the sea. National Oceanic and atmospheric Administration, Silver Spring, p 119-139

IPCC WGIII (1990) Climate change: the IPCC response strategies. Island Press, Washington, DC

IPCC CZMS (1991) Common methodology for assessing vulnerability to sea-level rise. Report of the Coastal Zone M anagement Subgroup, IPCC Response Strategies Working Group, Ministry of Transport, Public Work and Water M anagement, The Hague

IPCC (1996) Climate change 1995. Impacts, adaptations and mitigation of climate change: scientific-technical analysis. Watson RT, Zinyowera MC, M oss RH (eds). Cambridge University Press, Cambridge

Kay R, Hay J (1993) A decision support approach to coastal vulnerability and resilience assessment: a tool for integrated coastal zone management. In: M cLean R, Mimura N (eds) Vulnerability assessment to sea-level rise and coastal zone management. Proceedings of the IPCC Eastern Hemisphere Workshop. Secretariat of Eastern Hemisphere Workshop, Tokyo, p 213-225

Kay R, Elisara-Laula FM, Cole RC, Yamada K (1993) Assessment of coastal vulnerability and 
resilience to sea-level rise and climate change, case study: Upolu Island, Western Samoa, phase I: concept and approach. South Pacific Regional Environment Programme, A pia, and Environment Agency of J apan, Tokyo Maclver DC (ed) (1998) Adaptation to climate variability and change. Workshop Summary, Atmospheric Environment Service, Environment Canada, Ontario

Mimura N, Nunn PD (1997) Trends of beach erosion and shoreline protection in rural Fiji. J Coastal Res 14:37- 46

Mimura N, Plesikoti N (1997) Vulnerability of Tonga to future sea-level rise. J Coastal Res Spec Issue 24:117-132

Nunn PD, Mimura N (1997) Vulnerability of South Pacific island nations to sea-level rise. In: Leatherman SP (ed) Island states at risk, global climate change, development and population. J Coastal Res Spec Issue 24:133-151

Nunn PD, Ravuvu AD, Kay R, Yamada K (1993) Assessment of coastal vulnerability and resilience to sea-level rise and climate change, case study: Viti Levu Island, Fiji, phase I: concept and approach. South Pacific Regional Environment Programme, A pia, and Environment Agency of J apan, Tokyo

Nunn PD, Ravuvu AD, Aalbersberg W, Mimura N, Yamada K (1994a) Assessment of coastal vulnerability and resilience to sea-level rise and climate change, phase II, case study: Yasawa Islands, Fiji. South Pacific Regional Environment Programme, Apia, and Environment Agency of Japan, Tokyo
Nunn PD, Ravuvu AD, Balogh E, Mimura N, Yamada $K$ (1994b) Assessment of coastal vulnerability and resilience to sea-level rise and climate change, phase II, case study: Savai'i Island, Western Samoa. South Pacific Regional Environment Programme, A pia, and Environment Agency of J apan, Tokyo

Nunn PD, Aalbersberg W, Clarke CC, Korovulavula I, Mimura N, Ohno E, Yamada K, Serizawa M, Nishioka S (1996) Coastal vulnerability and resilience in Fiji, assessment of climate change impacts and adaptation, phase IV. South Pacific Regional Environment Programme, Apia, and Environment Agency of J apan, Tokyo

Ohno E, Mimura N, Yamada K (1996) M easurement of household's benefit from countermeasures against sea-level rise in small island country. Proceedings of the 5th World Conference of the Regional Science Association International, Tokyo, CS1-14-3-(1) CS1-14-3-(8)

Sem G, Campbell J R, Hay J E, M imura N, Ohno E, Yamada K, Serizawa M, Nishioka S (1996) Coastal vulnerability and resilience in Tuvalu, assessment of climate change impacts and adaptation, phase IV. South Pacific Regional Environment Programme, A pia, and Environment Agency of J apan, Tokyo

Yamada K, Nunn PD, Mimura N, Michida S, Yamamoto M (1995) M ethodology for the assessment of vulnerability of South Pacific island countries to sea-level rise and climate change. J Global Environ Eng 1:101-125 